\title{
Patrimônio cultural indígena: desafios para uma educação patrimonial decolonial
}

\author{
Indigenous cultural heritage: challenges for decolonial patrimonial \\ education
}

\section{Patrimonio cultural indígena: desafíos para una educación patrimonial decolonial}

\section{Sandro Guimarães de Salles}

Universidade Federal de Pernambuco, Programa de Pós-graduação em Educação Contemporânea e do Programa de Pós-graduação em Música - Música e Sociedade,

Professor

https://orcid.org/0000-0003-2398-4770

\section{Saulo Ferreira Feitosa ${ }^{2}$}

Universidade Federal de Pernambuco, Centro Acadêmico do Agreste, Programa de Pósgraduação em Educação Contemporânea, Professor do Curso de Medicina e do Curso de

Licenciatura Intercultural Indígena

https://orcid.org/0000-0001-6360-0212

\section{Rosane Freire Lacerda ${ }^{3}$}

Universidade Federal de Pernambuco, Centro Acadêmico do Agreste, Professora Adjunta do Curso de Medicina

https://orcid.org/0000-0002-3096-2089

Resumo: No Brasil, a cultura indígena tem sido reconhecida como parte do patrimônio cultural nacional. Assim, desde que foi criado o Programa Nacional do Patrimônio Imaterial, em 2000, os bens culturais indígenas têm sido objeto de inventários patrimoniais. Essa presença indígena nas políticas patrimoniais, no entanto, ainda não foi devidamente analisada. No presente artigo, procuramos contribuir para essa análise, partindo de uma reflexão crítica sobre a legislação e as políticas públicas nacionais sobre patrimônio e educação patrimonial. Concluímos que, para a potencialização do acesso dos indígenas a tais políticas, faz-se necessário assumir um diálogo mais equânime, além de mudanças epistêmicoconceituais e metodológicas que contemplem as relações interétnicas e o exercício interepistêmico.

Palavras-chave: Povos indígenas. Patrimônio cultural. Educação patrimonial.

Doutor em Antropologia pelo Programa de Pós-Graduação em Antropologia da Universidade Federal de Pernambuco; Mestre em História pela Pontifícia Universidade Católica de Goiás.

Doutor em Bioética pela Universidade de Brasilia; Mestre em Ciências da Saúde pela Universidade de Brasilia.

Doutora em Direito, Estado e Constituição pelo Programa de Pós-Graduação em Direito da Universidade de Braślia; Mestra em Direito, Estado e Constituição pelo Programa de Pós-Graduação em Direito da Universidade de Braślia. 
Abstract: In Brazil, indigenous culture has been recognized as part of the nacional cultural heritage. Thus, since it has been created the Programa Nacional de Patrimônio Imaterial (National Program of Intangible Heritage) in 2000, indigenous cultural assets has been subject of patrimonial inventories. This indigenous presence in patrimonial policies, nevertheless, hasen't been properly analized. In this article, we seek to contribute to this analyze, starting from an critical reflexion about the legislation and the national heritage public policies and patrimonial education. It is concluded that, in order to enhance the indigenous access to such policies, it is necessary to assume an more equitable dialogue, as well as epistemic-conceptual and methodological changes that contemplate the interethnic relations and the interepistemic exercise.

Keywords: Indigenous people. Cultural heritage. Patrimonial education.

Resumen: En Brasil, la cultura indigena ha sido reconocida como parte del patrimonio cultural nacional. Así, desde que se creó el Programa Nacional del Patrimonio Inmaterial, en 2000, los bienes culturales indígenas han sido objeto de inventarios patrimoniales. Esta presencia indígena en las políticas patrimoniales, sin embargo, aún no ha sido debidamente analizada. En el presente artículo, buscamos contribuir a ese análisis, partiendo de una reflexión crítica sobre la legislación y las políticas públicas nacionales sobre patrimonio y educación patrimonial. Concluimos que, para la potenciación del acceso de los indígenas a tales políticas, se hace necesario asumir un diálogo más ecuánime, además de cambios epistémicoconceptuales y metodológicos que contemplan las relaciones interétnicas y el ejercicio interepistémico. Palabras clave: Pueblos indígenas. Patrimonio cultural. Educación patrimonial.

Recebido em 28 de junho de 2018 Aceito em 10 de junho de 2019 Publicado em 24 de julho de 2019

\section{INTRODUÇÃO}

Nos países ocidentais, a noção de patrimônio cultural nacional se desenvolveu vinculada ao processo de industrialização e ao surgimento dos chamados Estados-nação, estando ligada à construção das narrativas de "memórias" e de identidades ditas "nacionais", forjadas no vínculo comum com o Estado territorial moderno. Introduzida com os processos de independência criolla no início do século XIX, essa concepção de identidade nacional foi, desde então, se desenvolvendo nos países latino-americanos, revelando a construção de sociedades reprodutoras do modelo colonial nas suas vivências internas, intra-territoriais. A colonialidade, como atributo, foi se desenvolvendo, desde então, como marca definidora das sociedades latinoamericanas que, como nos lembra Quijano, obtiveram "sua independência política, sem que isso implicasse semelhante descolonização das relações de poder." (QUIJANO, 1992, p. 74). 
Herdeira de uma tendência predominante em todo o Ocidente, a concepção de patrimônio cultural nacional desenvolvida na América Latina sempre esteve diretamente moldada por essa perspectiva colonial, na qual interesses dos grupos dominantes determinam seus usos e significados. Assim, a noção de patrimônio cultural nacional, em vez de anódina, ou seja, esvaziada em termos políticos, pode trazer em si um conteúdo de disputa de sentidos, podendo ser compreendida a partir do que sugere Zizek (1998, p. 142): “...] la lucha por la hegemonía ideológica y política siempre es, por lo tanto, la lucha por la apropiación de términos que se sienten 'espontáneamente' como apolíticos, como si trascendieran las fronteras políticas."

0 presente artigo é fruto das pesquisas desenvolvidas no projeto Educação Patrimonial e Cartografia Arqueológica do Agreste Central de Pernambuco, vinculado ao Programa de Pós-Graduação em Educação Contemporânea da Universidade Federal de Pernambuco e ao Laboratório de Antropologia da mesma Instituição. Muito das questões aqui colocadas é resultado das nossas pesquisas com os povos indígenas em Pernambuco, bem como da nossa atuação como docentes na referida Pós-graduação e na Licenciatura Intercultural Indígena da UFPE.

0 artigo faz uma hermenêutica crítica das discursividades sobre patrimônio cultural e educação patrimonial, analisando, sobretudo, as normas internacionais e a legislação e políticas públicas nacionais sobre o tema diante do reconhecimento da cultura indígena como integrante do patrimônio cultural nacional brasileiro. Procuramos mostrar que, apesar dos avanços, sobretudo nas últimas duas décadas, essas políticas tendem a adotar um caráter funcional, supostamente apolítico e universal.

\section{SITUANDO O PATRIMÔNIO CULTURAL}

As primeiras ações voltadas para o patrimônio cultural nacional no Brasil surgem em meados do século XIX, comprometidas com a construção de uma memória e identidade nacionais, preocupações próprias do contexto pós-independência. Em 1838, é criado o Instituto Histórico e Geográfico Brasileiro ( $(\mathrm{HGB})$ e o Arquivo Nacional, ambos com a finalidade de construir e preservar uma memória nacional. Transcorridos quase 100 anos, com a Constituição Federal de 1934, promulgada no contexto da política populista de Getúlio Vargas, é mencionada a proteção aos "objetos de interesse histórico e ao patrimônio artístico do País", que ficaria sob responsabilidade da União, dos estados e dos municípios. No mesmo ano é criada a Inspetoria dos Monumentos Históricos Nacionais, ligada ao Museu Histórico Nacional. Três anos depois, no contexto do Estado Novo, é criado o Serviço do Patrimônio Histórico e Artístico Nacional (SPHAN). Desde sua fundação até 1967, ou seja, durante três 
décadas, o órgão foi presidido por Rodrigo Melo Franco de Andrade, representante de uma elite intelectual que assumia a missão de manter o processo de civilização desenvolvido no País, desde a colonização portuguesa. Sob essa ótica, tal missão era por ele concebida "como uma 'tradição' que assegura a continuidade da nação brasileira." (GONÇALVES, 2002, p. 42).

No contexto do SPHAN, a educação chega a ser reduzida a um mero instrumento de persuasão, capaz de fazer com que o povo brasileiro reconhecesse o valor do patrimônio artístico e dos monumentos históricos, como se lê na fala seguinte de Rodrigo Melo Franco de Andrade:

\footnotetext{
Em verdade, só há um meio eficaz de assegurar a defesa permanente do patrimônio de arte e história do pais: é a educação popular. Ter-se-á de organizar e manter uma campanha ingente visando a fazer o povo brasileiro compenetrar-se do valor inestimável dos monumentos que nos ficaram do passado. Se não se custou muito persuadir nossos concidadãos de que o petróleo do país é nosso, incutir-thes a convicção de que o patrimônio histórico e artístico do Brasil também é deles ou nosso, será certamente praticável. (ANDRADE, 1987, p. 64).
}

Em seu discurso, Andrade (1987) afirma ser o povo brasileiro o responsável pelo insucesso das políticas de preservação do patrimônio nacional, os "monumentos do passado". Expressa, desse modo, uma política não dialógica, que ignora o contexto social e econômico dos detentores do bem. A educação, nesse contexto, é pensada como uma forma particular de desenvolvimento intelectual, um processo de "refinamento" da sociedade, que teria sua origem no pensamento liberal do século XIX, fundamentado na ideia de igualdade entre todos os homens e todas as mulheres. "De acordo com esta ideia, se uma igualdade efetiva não existe no presente, a possibilidade da aculturação significa que cada um é, ao menos potencialmente, igual a todos os demais." (YOUNG, 2005, p. 39). Como a própria colonização europeia, a educação, enquanto um caminho supostamente capaz de conduzir o mundo para o desenvolvimento e refinamento intelectual, seria concebida como "um benefício inestimável".

A partir de 1967, em plena Ditadura Militar, o arquiteto Renato Soeiro assume a direção do SPHAN. Em consonância com os ideólogos da formação da genuína identidade brasileira pós-independência, os militares viam na noção de patrimônio cultural uma possibilidade de fortalecimento da unidade nacional. Alinhado com esse propósito, Soeiro investe na preservação das áreas urbanas, bem como no potencial turístico do patrimônio. Ainda no contexto da sua gestão, em 1970, é criado o Instituto do Patrimônio Histórico e Artístico Nacional (IPHAN). Para alguns, o arquiteto teria contribuído para o processo de modernização administrativa do Iphan e para a democratização das questões relacionadas ao patrimônio (SANT'ANNA, 2009, 2015). 
Por quatro décadas - de sua fundação, no contexto do SPHAN, até o final dos anos 1970 -, o IPHAN esteve voltado para a proteção dos bens patrimoniais nacionais considerados de excepcional valor histórico e artístico, limitando-se às obras de arte, ao patrimônio natural, às edificações e monumentos históricos de origem europeia. 0 patrimônio edificado, denominado de "pedra e cal" (igrejas barrocas, fortes, casas-grandes, etc.), recebia uma atenção especial.

A partir dos anos 1970, influenciado pelo debate em outros países (MESTRE; CARDONA, 2006; HAFSTEIN, 2014), o debate sobre o patrimônio cultural brasileiro passa a incorporar os discursos sobre a valorização do patrimônio cultural intangível e democratização do acesso à cultura. Em parte, essas novas narrativas são desencadeadas pela reação à aprovação, em 1972, da Convenção da Unesco para a Proteção do Patrimônio Mundial, Cultural e Natural. ${ }^{4}$ Esta limitava a concepção de patrimônio às obras do homem ou da natureza, consideradas de "valor universal excepcional do ponto de vista da história, da arte ou da ciência", ou "do ponto de vista histórico, estético, etnológico ou antropológico."5 (UNESCO, 1972).

Adquirem protagonismo nesse novo cenário as culturas populares, que passam a ser concebidas, por alguns, como dimensão fundante do patrimônio nacional. Nesse contexto, destaca-se a atuação do designer pernambucano Aloísio Magalhães, que ajuda a fundar, em 1975, o Centro Nacional de Referência Cultural (CNRC). Aloísio assume, em 1979, a direção do IPHAN, adotando uma política distanciada das concepções que marcaram as políticas patrimoniais no Brasil por mais de quatro décadas. Assim, interessa-se pela diversidade e dinâmica cultural do Brasil, com ênfase no presente e não no passado (GONÇALVES, 2002).

Essas novas narrativas nacionais influenciam a Constituição Federal de 1988, que diz em seu art. 216: “Constituem patrimônio cultural brasileiro os bens de natureza material e imaterial, tomados individualmente ou em conjunto, portadores de referência à identidade, à ação, à memória dos diferentes grupos formadores da sociedade brasileira [...]"6 (BRASIL, 1988).

Na Carta de Fortaleza, produzida no Seminário Patrimônio Material: Estratégias e Formas de Proteção, em comemoração aos 60 anos de fundação do IPHAN, são propostas diversas ações, entre elas que o IPHAN promova, juntamente com outras unidades vinculadas

4 Uma das críticas partiu do Governo da Bolivia, que enviou uma carta à Unesco, argumentando que os instrumentos legais propostos não contemplariam as formas de expressão do seu país (em geral, ligadas às culturas indigenas), que vinham sendo objeto de exportação clandestina. Esse mesmo Governo, no entanto, confiscou terras indígenas e negou suas identidades étnicas, levando os Quechua e Aymára, entre outros, a uma pobreza extrema. Tudo isso acontecia enquanto as expressões culturais desses povos eram celebradas pelo Governo de Banzer, que se apropriava desse patrimônio, transformando-o na cultura nacional (HAFSTEIN, 2014).

5 Aprovada em 1972, durante a 17. reunião da Unesco realizada em Paris.

6 Não há, no texto acima, referência direta aos povos indígenas, mas aos «diferentes grupos formadores da sociedade brasileira." Estes teriam sua identidade, ação e memória como parte do patrimônio cultural brasileiro. Já no art. 215, lêse: "0 Estado protegerá as manifestações das culturas populares, indigenas e afro-brasileiras, e das de outros grupos participantes do processo civilizatório nacional." (BRASIL, 1988). 
ao Ministério da Cultura, o inventário dos bens culturais de natureza imaterial "em âmbito nacional, em parceria com instituições estaduais e municipais de cultura, órgãos de pesquisa, meios de comunicação e outros" (INSTITUTO DO PATRIMÔNIO HISTÓRICO E ARTÍSTICO NACIONAL - IPHAN, 1997). 0 documento destaca que nesses inventários deve ser dada uma "especial atenção" aos bens culturais referentes à cultura popular. A Carta traz ainda seis moções, entre eles uma moção de apoio às expressões culturais dos povos ameríndios: "pelo reconhecimento da cultura indígena como integrante do patrimônio cultural nacional brasileiro, devendo, a exemplo de outras etnias, ser objeto de atenção dos órgãos do Ministério da Cultura." (INSTITUTO DO PATRIMÔNIO HISTÓRICO E ARTÍSTICO NACIONAL - IPHAN, 1997).

Três anos após a referida Carta, é instituído, pelo Governo Federal, por meio do Decreto n. 3.551, de 4 de agosto de 2000, o Registro de Bens Culturais de Natureza Imaterial e criado o Programa Nacional do Patrimônio Imaterial (PNPI) (BRASIL, 2000). No mesmo ano, - IPHAN adota a metodologia do Inventário Nacional de Referências Culturais (INRC), que se torna o principal instrumento para a realização dos inventários patrimoniais (DEPARTAMENTO DE IDENTIFICAÇÃO E DOCUMENTAÇÃO - IPHAN, 2000). 0 inventário, que consiste na pesquisa sistemática sobre o bem, é uma das etapas do processo de patrimonialização. Com essas novas diretrizes, diversas manifestações culturais - enquanto bens culturais imateriais - são identificadas, documentadas e registradas como Patrimônio Cultural Brasileiro.

Dos dois primeiros registros feitos no contexto do INRC, ambos realizados em 2002, um foi a Arte Kusiwa, representação gráfica do povo Wajãpi, localizado no Estado do Amapá. ${ }^{7}$ Do total de 41 bens culturais registrados como patrimônios culturais brasileiros, sete são de povos indígenas, além de dois que se encontram entre os 34 bens em processo de instrução para registro.

Também no contexto do IPHAN, o Governo Federal instituiu, por meio do Decreto n. 7.387, de 9 de dezembro de 2010, o Inventário Nacional da Diversidade Linguística (INDL) (BRASIL, 2010). Dos sete inventários realizados, seis são de indígenas localizados nos Estados do Amapá, Amazonas, Mato Grosso, Santa Catarina e Tocantins.

Essa presença dos povos indígenas nas políticas patrimoniais - assim como outras questões também relacionadas aos bens não indígenas - ainda não foi devidamente analisada. Apesar de os inventários terem envolvido o trabalho de antropólogos e outros profissionais das humanidades, a discussão em torno das políticas patrimoniais esteve, em sua maioria, voltada apenas para questões metodológicas, ou seja, ao "como fazer". Assim, como observa Salles (2014, p. 103) a respeito do cotidiano da pesquisa, 
[..] o pesquisador é envolvido na dinâmica do processo, que inclui cronogramas, reuniões, planejamento, além de questões de ordem burocrática e administrativa, restando pouco (ou nenhum) tempo para reflexões sobre sua própria prática. As tensões são minimizadas na fuga para a necessidade real do cumprimento dos prazos, acordos e contratos assinados.

Isto significa que, para a complexa perspectiva que a diversidade exige, o "como fazer" é insuficiente, pois se tomado como único ou principal critério, as diferenças tendem a ser naturalizadas e despolitizadas, tratadas de modo acrítico. Como argumentou Walsh (2009), a diversidade cultural, a partir dos anos 1990, tornou-se um tema em moda, estando presente nas políticas públicas, nas reformas educacionais, etc. Embora tenha sido resultado da luta dos movimentos sociais por direitos civis e direito à diferença, essa presença nas políticas públicas se assentaria na retórica discursiva de reconhecimento e respeito à diversidade cultural, fortemente vinculada à lógica do multiculturalismo neoliberal. Este desvincula das ideias de diferença e diversidade dos sujeitos indígenas, negros e mestiços do Continente toda a sua condição de subalternidade social, cultural, econômica e política, invisibilizando, portanto, sua sujeição ao domínio colonial eurocentrado. Conforme a autora, o conceito de multiculturalismo

\footnotetext{
[... incorpora a diferença, na medida em que a neutraliza e a esvazia de seu significado efetivo. Nesse sentido, o reconhecimento e respeito à diversidade cultural se convertem em uma nova estratégia de dominação que ofusca e mantém, ao mesmo tempo, a diferença colonial através da retórica discursiva do multiculturalismo e sua ferramenta conceitual, a interculturalidade "funcional", entendida de maneira integracionista. (WALSH, 2009, p. 16).
}

A interculturalidade funcional, portanto, promove a abertura para a diferença, ao mesmo tempo que assegura o seu controle e domínio. Desse modo, seriam mantidos o poder institucional-estrutural e, consequentemente, as desigualdades sociais. Contrapondose a essa perspectiva, a interculturalidade crítica consiste em um projeto político, social e epistêmico, que assume a perspectiva da decolonialidade. Enquanto a interculturalidade funcional promove o diálogo sem tocar nas causas da assimetria social e cultural, a interculturalidade crítica busca eliminar essas causas (TUBINO, 2004).

No Brasil, parte das políticas de patrimônio cultural vigentes, no que diz respeito aos grupos étnicos, adquire um caráter assimilacionista e assimétrico, à medida que operam a partir de uma aparente inclusão desses grupos, "naturalizando a diferença e ocultando as desigualdades." (WALSH, 2009). Assim, partindo dos questionamentos de Santos (2002, p. 30), não haveria diálogo na interculturalidade funcional ou no multiculturalismo neoliberal quando se reduz as culturas ao silêncio, tornando impronunciáveis seus saberes, suas 
filosofias, suas epistemologias. Dito de outro modo: "como fazer falar o silêncio sem que ele fale necessariamente a linguagem hegemónica que o pretende fazer falar?"

\section{CONTEXTUALIZANDO A EDUCAÇÃO PATRIMONIAL}

0 termo educação patrimonial é de uso recente, sendo empregado pelo IPHAN apenas a partir dos anos 1990. Seu uso também não é consensual, havendo quem prefira expressões como "educação para o patrimônio", "educação com o patrimônio", "patrimônio e educação", entre outros (GIL; POSSAMAl, 2014). Se considerarmos, no entanto, que a educação está presente sempre que surgem formas de condução e controle do ensinar-e-aprender, dentro ou fora da escola (BRANDÃ0, 2007), as ações em torno do patrimônio cultural já contemplariam, de certo modo, uma dimensão educativa.

As primeiras experiências com o que tem sido hoje denominado de educação patrimonial remetem aos espaços museais, enquanto ambientes privilegiados para atividades educativas. Esses espaços também têm sido utilizados pelos povos indígenas, que vão conferir um novo sentido à museologia tradicional, eurocêntrica. Considerando que uma análise exaustiva dessas experiências fugiria aos propósitos mais imediatos do presente artigo, nos limitaremos a uma breve referência ao museu Magüta, criado no início dos anos 1990 para promover a cultura dos Tikuna, povo indígena localizado na região do Alto Solimões, no Estado do Amazonas. A respeito do museu, a antropóloga Regina Abreu fez o seguinte questionamento: "Como e por que uma sociedade indígena apropriava-se do 'museu', uma instituição marcadamente racionalista fundada num projeto universalista de difusão do conhecimento produzido nas academias e nos centros de pesquisa?" (ABREU, 2012, p. 285).

0 museu começa a ser organizado em 1988, no contexto da luta dos Tikuna pela defesa do seu território, que resultou, naquele ano, na morte de 14 indígenas em uma emboscada. Contudo, com a intensa participação dos Tikuna, ele foi criado, sendo considerado de fundamental importância para a luta e (re)organização do povo. Em 1995, o museu foi premiado como Museu Símbolo pelo International Council of Museums. No mesmo ano, recebeu - Prêmio Rodrigo Melo Franco de Andrade, concedido pelo IPHAN pela sua contribuição à preservação da memória cultural brasileira. A diferença do museu Magüta em relação a outros museus, inclusive etnográficos, é que consiste em uma experiência realizada pelos próprios indígenas, construída no contexto da luta pela terra. 
experiência museológica na primeira pessoa. Diversamente do padrão dos demais museus etnográficos, este se constituiu como um museu engajado, articulado com as lutas do grupo Tikuna. (ABREU, 2012, p. 291).

No que tange à educação, o museu foi construído no período em que a escola chega às aldeias, se configurando como uma experiência diferenciada de educação escolar indígena. Por outro lado, um trabalho desenvolvido de interação entre as escolas da cidade e os Tikuna promoveu uma melhor relação entre os índios e a comunidade local não indígena (FREIRE, 1999). Esse e outros exemplos de museus indígenas, portanto, vêm contribuindo para ressemantizar os espaços museais e imprimir um novo sentido à museologia eurocentrada, bem como às concepções coloniais de patrimônio e educação patrimonial.

Outro espaço onde vem sendo desenvolvidas ações de educação patrimonial e que dialoga, direta ou indiretamente, com as questões indígenas é a Arqueologia. Na própria demarcação dos seus territórios, muitos povos fizeram uso de marcadores arqueológicos, que se encontram dentro de seus territórios tradicionais, a exemplo de furnas, cemitérios indígenas, entre outros. Destacamos, ainda, a perspectiva decolonial, proposta por arqueólogos sul-americanos que, ao pesquisarem os bens arqueológicos dos povos andinos, partem da premissa de que seria necessário repensar a arqueologia eurocentrada. Para Gnecco (2016), não só a pesquisa arqueológica, mas a educação patrimonial na arqueologia seria marcada pela colonialidade, pois seria realizada no contexto de políticas corporativas e não comprometidas com o bem comum. Assim, questiona-se o lugar (epistêmico e político) das sociedades e dos indivíduos situados fora do mundo eurocêntrico, defendendo uma arqueologia alinhada com a discussão contemporânea sobre decolonialidade.

No que diz respeito aos povos indígenas, o debate sobre educação patrimonial deve considerar, entre outros aspectos, não apenas as especificidades desses povos em relação aos demais grupos étnicos no Brasil, mas as diferenças sócio-étnico-culturais existentes entre os próprios povos indígenas. Pensamos ser este o primeiro desafio na promoção de políticas patrimoniais voltadas ao patrimônio cultural indígena. Não há, por assim dizer, um patrimônio genérico, uni-identitário, mas práticas diversas, que se manifestam em uma multiplicidade de saberes, celebrações e modos de fazer próprios a cada povo. Assim, ainda que algumas práticas sejam comuns a diferentes grupos, elas tendem a apresentar idiossincrasias no que tange a sua realização e sentidos. Serve de exemplo o Toré, dança ritual praticada pelos indígenas no Nordeste, sendo um dos elementos empregados na afirmação de sua identidade étnica. Apesar das aproximações, o ritual possui forma, sentido e saberes, inclusive segredos, próprios a cada povo. 0 mesmo pode ser dito com relação a alguns bens indígenas já patrimonializados, como a Cachoeira de lauaretê, que é referência para os povos indígenas dos Rios Uaupés e Papuri; e o Sistema Agrícola Tradicional do Rio Negro, que está associado a 22 povos dos troncos linguísticos Tukano Oriental, Aruak e Maku, 
localizados ao longo do Rio Negro. Os demais bens culturais patrimonializados, quais sejam: a Arte Kusiwa, dos Wajãpi; o Modo de Fazer Bonecas Karajá, a Ritxòkò, enquanto Expressão Artística e Cosmológica do Povo Karajá; o Ritual Yaokwa, do povo Enawene Nawe, no Noroeste do Mato Grosso; e a Tava, lugar de referência para o povo Guarani-Mbyá, são referências para um único povo.

Embora reconhecendo a importância de ações que reconheçam e valorizem os saberes indígenas e seus patrimônios, como os inventários indigenas já realizados, é preciso ampliar os critérios empregados na seleção dos bens ou dos povos que devem ser priorizados no processo de patrimonialização, na perspectiva de contemplar a pluridiversidade dos povos indígenas.

Em um primeiro momento, considerando que dos 41 bens registrados como patrimônio cultural brasileiro sete são indigenas, e das sete linguas inventariadas no contexto do Inventário Nacional da Diversidade Linguística seis são indígenas, o número de bens indigenas inventariados pode parecer significativo. Se levarmos em consideração, no entanto, a existência de mais de 305 povos e 274 línguas indigenas existentes no território brasileiro (IBGE, 2010), esse número se mostra irrelevante. Por outro lado, apesar de o Nordeste possuir a segunda maior população indigena do Brasil, teve apenas um único bem inventariado (mas ainda não registrado), o Oficio Tradicional das Parteiras Indigenas de Pernambuco.

Percebemos, portanto, que o problema se liga à concepção vigente de patrimônio cultural e à impossibilidade de inserir os povos indígenas, por suas especificidades e diferenças, em um discurso de inventário nacional, vinculado à concepção de identidade "nacional", que, como mencionado, tem sido forjada no vínculo comum com o Estado territorial moderno.

Uma possibilidade de os povos indigenas terem seus patrimônios culturais reconhecidos, contemplando sua pluridiversidade, consiste em tomar como referência a Convenção 169 da Organização Internacional do Trabalho (OIT), ratificada pelo Brasil em 2004. Em seu artigo $1^{\circ}$, a Convenção adota a autoidentificação como um critério legítimo na definição dos povos indígenas. Em seu artigo $4^{\circ}$, reconhece que cabe ao Estado "salvaguardar as pessoas, instituições, bens, trabalho, culturas e meio ambiente desses povos." (ORGANIZAÇÃO INTERNACIONAL DO TRABALHO, 2012, p. 17). Esse processo, no entanto, deve ser dialógico, devendo os povos ser consultados "sempre que sejam previstas medidas legislativas ou administrativas suscetíveis de afetá-los diretamente." Nesses casos, o Estado deve assegurar a participação dos povos indígenas na "formulação, implementação e avaliação de planos e programas de desenvolvimento nacional e regional que possam afetá-los diretamente." (ORGANIZAÇÃO INTERNACIONAL DO TRABALHO, 2012, p. 18-19).

Tomando a Convenção como referência, podemos afirmar que ao aceitar a identificação como legítima, o Estado deveria reconhecer, igualmente, seu patrimônio cultural. 
Caberia a esse povo, portanto, a definição do que seriam seus bens culturais, sobretudo por se tratar de aspectos ligados "a sua vida, crenças, instituições, bem-estar espiritual." (ORGANIZAÇÃO INTERNACIONAL DO TRABALHO, 2012, p. 19). Competiria ao Estado apenas a tarefa de chancelar esse patrimônio.

\section{PATRIMÔNIO CULTURAL E A PERSPECTIUA DECOLONIAL}

A opção aqui feita pelo uso da palavra "decolonial" advém da compreensão sobre a importância política e epistemológica do termo, muito bem justificado por Cathrine Walsh, sua criadora. De acordo com Mignolo (2008, p. 246, grifo do autor),

El empleo de de-colonial, en vez de des-colonial (con o sin guión), lo propuso Catherine Walsh como manera de distinguir entre la propuesta decolonial del proyecto modernidad/colonialidad, por un lado, del concepto de "descolonización" en el uso que se le dio durante la Guerra Fría, y, por otro, de la variedad de usos del concepto de "post-colonialidad".

Por essa razão, e em razão da origem da palavra "patrimônio" - que, não obstante sua ressignificação ao longo da história ocidental, ainda carrega consigo as marcas das antigas sociedades patriarcais patrimonialistas -, defende-se aqui que o paradigma da decolonialidade possibilita explicitar melhor as possibilidades e limites das políticas públicas sobre patrimônio no tocante aos interesses e necessidades dos povos indígenas e populações tradicionais no Brasil.

A questão aqui colocada é a seguinte: estando a noção de patrimônio na modernidade vinculada ao surgimento dos Estados-nacionais, que são pretensamente monoculturais, que lugar ocupam os povos originários e as populações tradicionais nas políticas públicas destinadas a salvaguardar os patrimônios ditos "nacionais"? Essa indagação implica tanto a concepção sobre patrimônio quanto a compreensão sobre a quem compete salvaguardá-lo e quais devem ser seus verdadeiros detentores.

Como bem observa Fonseca (1996, p. 85), “Quando se fala em referências culturais, se pressupõem sujeitos para os quais essas referências façam sentido (referências para quem?)" Há, portanto, uma questão anterior que está intrinsecamente ligada às próprias filosofias de cada povo, nação ou comunidades tradicionais. Estão envolvidos valores, crenças, memórias, etc. Os sujeitos coletivos serão sempre os responsáveis pelo estabelecimento dos critérios definidores do que é patrimônio cultural para aquela cultura específica, localizada, 
territorializada e dinamicamente atualizada, o que evidencia que o próprio conceito de patrimônio também é dinâmico, podendo ser historicamente reinventado.

Conforme Gallois (2006, p. 8), ao participar de certo evento ${ }^{8}$ e ser solicitado a explicitar o que entendia sobre patrimônio imaterial, o indígena João Asiwefo, do povo Tiriyó, localizado no Estado do Pará, fez uso do desenho de um jovem indígena para exemplificar sua compreensão:

Todos nós sabemos que o imaterial é a fonte do patrimônio material. Para nós, é entu, fonte. Está na cabeça desse rapaz que desenhamos, está no pensamento dele. Se ele não tiver esse conhecimento dentro dele, como é que ele vai fazer os enfeites que ele está usando aqui, como é que ele vai poder repassar para os filhos dele? 0 patrimônio imaterial é o conhecimento que foi repassado para esse rapaz. É o invisivel que está dentro, que comanda tudo. 0 conhecimento que ele tem para fazer os adornos que ele vai tecendo. Isso quer dizer que ele não deixou acabar o conhecimento.

Tomando como referência o conceito externado por Asiwefo, pode-se deduzir que é possível haver uma ideia universal sobre patrimônio. Contudo seu conteúdo será sempre particular (local). A expressão entu nos remete a uma palavra de origem grega, aesthesis, que significa "sensação, processo de percepção, sensação visual, sensação degustativa ou sensação auditiva." Dela derivou o vocábulo "sinestesia", que representa um entrecruzamento entre sentidos e sensações (MIGNOL0, 2010, p. 13). Aesthesis foi importada do grego antigo para as línguas europeias modernas. Embora inicialmente tenha sido mantido o seu significado original, a partir do século XVII sofreu um reducionismo, passando a significar "sensação do belo". 0 passo seguinte foi a instituição da estética como teoria e da arte como prática. Nesse processo se deu a colonização da aesthesis pela estética e, em uma perspectiva ainda mais reducionista, a noção de beleza da modernidade foi instituida por uma "etnoclase que hoy conocemos con el nombre de burguesia." (MIGNOLO, 2010, p. 14).

Tendo como referência os estudos decoloniais, é possivel afirmar que desse processo resultou, além da colonialidade epistêmica, e a ela ligada, também uma colonialidade cultural, através da qual se tornou possivel a imposição de um conteúdo particular, a estética burguesa, como um valor universal que passará a influenciar em toda definição sobre arte e por consequência na definição de patrimônio cultural, dada sua vinculação com o campo das artes.

Em consequência desse processo de captura da aesthesis pela estética burguesa, a ideia de patrimônio inicialmente elaborada e já aqui explicitada, não poderia em hipótese alguma atender a todas as noções de patrimônio existentes em todas as culturas, 
uma vez que não existe nenhum determinante universal que vincule a aesthesis ou entu à beleza. Por esse motivo, mesmo quando pensado em uma perspectiva crítica, como também já foi citado, o conceito ocidental de patrimônio ainda reproduz a colonialidade epistêmica que necessita ser superada para que possa contemplar as diferenças (pluralidades) culturais com seus conteúdos locais.

Tendo enfrentado a discussão conceitual, faz-se necessário, ainda, refletirmos sobre a salvaguarda e os detentores do patrimônio. No ano de 2003, a Unesco aprovou a Convenção para a Salvaguarda do Patrimônio Cultural Imaterial, cujo texto foi promulgado no Brasil pelo Decreto n. 5.753, de 12 de abril de 2006. Em seu artigo 2.1, a Convenção apresenta a seguinte definição de patrimônio cultural imaterial:

Entende-se por "patrimônio cultural imaterial" as práticas, representações, expressões, conhecimentos e técnicas - junto com os instrumentos, objetos, artefatos e lugares culturais que thes são associados - que as comunidades, os grupos e, em alguns casos, os individuos reconhecem como parte integrante de seu patrimônio cultural. Este patrimônio cultural imaterial, que se transmite de geração em geração, é constantemente recriado pelas comunidades e grupos em função de seu ambiente, de sua interação com a natureza e de sua história, gerando um sentimento de identidade e continuidade e contribuindo assim para promover o respeito à diversidade cultural e à criatividade humana. Para os fins da presente Convenção, será levado em conta apenas o patrimônio cultural imaterial que seja compativel com os instrumentos internacionais de direitos humanos existentes e com os imperativos de respeito mútuo entre comunidades, grupos e individuos, e do desenvolvimento sustentável. (BRASIL, 2006).

Entende-se, aqui, que o conceito de patrimônio apresentado no documento pretendeu ampliar o alcance, reconhecendo a autonomia dos grupos e comunidades em afirmar o que consideram como pertencentes aos seus patrimônios, representando um avanço na perspectiva de aumentar a inclusão de comunidades humanas nas políticas de proteção dos patrimônios culturais. Todavia, não basta este rol patrimonial ser reconhecido pelos membros da comunidade, necessitando, ainda, ser reconhecido pelo Estado. Assim, a autonomia das comunidades detentoras do patrimônio fica submetida à chancela estatal, e, para que isso ocorra, os membros da comunidade que reivindicam a sua salvaguarda deverão aceitar se submeter às regras previamente definidas pelas instituições credenciadas pelo Estado. Isso pode se converter em uma armadilha para capturar as diferenças e convertê-las em uma espécie de diversidade cultural legitimada, mas também disciplinada, controlada.

No caso dos povos ameríndios, cuja presença nos territórios tradicionais é anterior ao Estado, a situação torna-se ainda mais grave, já que seus patrimônios culturais, mesmo que sejam atualizados no tempo histórico, detêm uma anterioridade em relação ao 
período da invasão perpetrada pelos reinos de Espanha e Portugal durante os séculos XV e XVI. A Constituição brasileira de 1988 estabelece em seu artigo 231 que "são reconhecidos aos índios sua organização social, costumes, línguas, crenças e tradições [...]" e determina como obrigação da União Federal "proteger e fazer respeitar todos os seus bens." (BRASIL, 1988). Portanto, resta claro que os patrimônios indígenas já são constitucionalmente reconhecidos, cabendo apenas à União Federal garantir a sua proteção.

Dessa forma, as políticas do Estado brasileiro destinadas à proteção dos patrimônios deveriam respeitar essa determinação constitucional, assumindo a perspectiva da interculturalidade crítica, devendo sempre fazê-las a partir do estabelecimento do diálogo intercultural, por meio de consultas às comunidades e aos povos destinatários. Essa mudança promoveria uma aproximação com a noção de entu, apontando, assim, para uma perspectiva decolonial das referidas políticas. Na prática, significaria reconhecer que a salvaguarda dos patrimônios é exclusiva dos povos e comunidades que os detêm, sendo estes seus verdadeiros detentores, não podendo jamais aqueles serem usurpados pelo Estado e muito menos reduzidos a uma categoria abstrata de patrimônio nacional, mesmo porque, em geral, os povos originários possuem mais de uma nacionalidade. No caso do Brasil, por exemplo, não se reconhecem apenas como cidadãos brasileiros. Além da nacionalidade brasileira, há aquela correspondente à sua nação originária, o que evidencia o caráter plurinacional do Estado brasileiro, embora não haja essa explicitação no Texto Constitucional.

Assim como as políticas públicas, a educação patrimonial também necessita ser repensada e transformada. Durante os encontros promovidos pelo movimento dos professores indígenas no Brasil é comum se ouvir o mote "educação é um direito, mas tem que ser do nosso jeito". Essa frase nos chama a atenção sobre a necessidade de se levar em consideração as especificidades de cada povo indígena, fazendo-nos lembrar de que todos eles possuem sistemas educativos próprios que deverão ser considerados nas políticas de educação escolar indígena implementadas pelo Estado.

0 mesmo se aplica à educação patrimonial. Precisamos tomar consciência de que ela já existe em cada cultura indígena e é graças a sua existência que os patrimônios culturais indígenas vão sendo preservados e atualizados através das gerações. Nesse processo educativo participam todos os membros da comunidade e com eles interagem também alguns protagonistas do mundo sobrenatural. A ação dos espíritos, por exemplo, é sempre determinante para a manutenção de alguns objetos sagrados. Não é qualquer pessoa indígena que poderá produzi-los. Estes, geralmente, são feitos pelos detentores daqueles saberes que thes foram transmitidos pelos espíritos. Por sua vez, esses detentores também exercem um papel relevante na conscientização das pessoas sobre a importância da guarda e preservação dos objetos sagrados. 
A educação patrimonial é uma aliada fundamental na busca pela decolonialidade das relações culturais. Contudo, para que possa cumprir essa tarefa, requer mudanças metodológicas e novas formulações teóricas que contemplem as relações interétnicas e o exercício interepistêmico, tendo em vista o princípio da incompletude de todas as culturas e as possibilidades de reciprocidade e complementaridade entre elas. Esse seria o ponto de partida para se chegar a uma educação patrimonial decolonial.

\section{CONSIDERAÇÕES FINAIS}

Como podemos perceber ao longo do texto, durante as últimas décadas a noção de patrimônio cultural vem sendo modificada e ampliada, o que possibilitou que alguns grupos sociais, sobretudo as minorias étnicas, passassem a ser visibilizados e conquistassem o direito de ter seus patrimônios culturais reconhecidos. Essa conquista foi resultado de muitas lutas que envolveram as populações tradicionais, grupos culturais, movimentos sociais, comunidade acadêmica, artistas e intelectuais comprometidos com a causa nos mais diferentes países. Para garantir a efetivação desses direitos, vários instrumentos normativos foram construídos, tanto no plano internacional, a exemplo de declarações e convenções sobre a temática específica, quanto nacionalmente, com a inclusão dessas garantias nas legislações específicas de cada país.

Esse aparato legal tornou possivel a construção de políticas públicas voltadas para o registro, proteção e divulgação dos patrimônios culturais em todo o Planeta. Por meio da realização de inventários, pode-se promover a disponibilização, para as gerações atuais e futuras, de boa parte da produção patrimonial cultural humana. Nesse sentido, é importante destacar o art. 16 da Convenção para a Salvaguarda do Patrimônio Cultural Imaterial, que definiu a criação de uma lista representativa do patrimônio cultural imaterial da humanidade.

Entendemos que esses avanços vão criando condições para que as novas narrativas sobre a história da humanidade tornem possível a inclusão das sociedades humanas que foram negligenciadas nos relatos históricos produzidos pelo 0cidente, todos eles arrogantemente construídos a partir dos feitos de suas chamadas "grandes civilizações", cujos legados foram exaltados e colocados em posição de superioridade em relação aos dos demais povos.

É certamente por perceberem essa importância que os povos e populações historicamente excluídos se mobilizam para acessarem as políticas públicas sobre patrimônio cultural. Não obstante, para viabilizar esse acesso, têm ainda que superar muitos obstáculos, como as excessivas exigências burocráticas justificadas por regras que limitam o exercício 
de suas autonomias. Tudo isso é relativizado tendo em vista um projeto de futuro capaz de corrigir uma injustiça histórica. Contudo, continuam a lutar para que os direitos conquistados não apenas sejam garantidos, mas principalmente avancem na perspectiva de incorporar novos conceitos que considerem seus saberes, suas filosofias, suas epistemologias, seus conceitos próprios sobre patrimônio cultural, assim como aquele do povo Tiryó, antes apontado.

Tendo em vista a importância desses elementos, nosso intuito foi apresentar uma reflexão crítica sobre o papel das normas internacionais e da legislação e políticas públicas nacionais sobre o patrimônio cultural e, na mesma perspectiva, contribuir para seu avanço e potencialização do acesso dos povos indígenas a tais políticas. Por essa razão, fazendo uso do pensamento decolonial, destacamos alguns elementos considerados como obstáculos à ampliação desse acesso. Esses elementos são constitutivos da colonialidade cultural que subjaz à noção de patrimônio cultural produzida pelo pensamento ocidental dominante, cuja origem está no chamado "norte global". Também nos foi possível constatar que, mesmo a partir dos instrumentos hoje disponíveis, pode-se assumir uma perspectiva decolonial no âmbito das ações voltadas à proteção do patrimônio cultural, inclusive aquelas que se destinam a promover uma educação patrimonial. Para que isso ocorra, faz-se necessário assumir a perspectiva da interculturalidade crítica como uma forma de diálogo intercultural mais equânime, em que se procure diminuir a distância criada pelo fosso cultural que classifica as culturas em superiores e inferiores. Uma forma de classificação que, embora historicamente naturalizada, é resultante do processo de colonização iniciado em fins do século XV, com a invenção do chamado "Novo Mundo" pelas nações europeias.

\section{REFERÊNCIAS}

ABREU, R. Museus indígenas no Brasil: notas sobre as experiências Tikuna, Wajãpi, Karipuna, Palikur, Galibi-Marworno e Galibi Kalína. In: FAULHABER, P.; DOMINGUES, H. M. B.; BORGES, L. C. (org.). Ciências e Fronteiras. Rio de Janeiro: Museu de Astronomia e Ciências Afins, 2012.

ANDRADE, R. M. F. Rodrigo e o SPHAN: coletânea de textos sobre o patrimônio cultural. Rio de Janeiro: Ministério da Cultura/Fundação Pró-Memória, 1987.

BRANDÃO, C. R. 0 Que é Educação. São Paulo: Editora Brasiliense, 2007.

BRASIL Constituição. República Federativa do Brasil de 1988. Brasilia, DF: Senado Federal, 1988. Disponível em: http://www.planalto.gov.br/ccivil_03/constituicao/constituicaocompilado.htm. Acesso em: 4 maio 2018.

BRASIL. Decreto n. 3.551, de 4 de agosto de 2000. Institui o Registro de Bens Culturais de Natureza Imaterial que constituem patrimônio cultural brasileiro, cria o Programa Nacional do Patrimônio Imaterial e dá outras providências. Diário Oficial da União, Brasília, DF, 7 ago. 2000. Disponível em: http://www. planalto.gov.br/ccivil_03/decreto/d3551.htm. Acesso em: 4 maio 2018. 
BRASIL. Decreto n. 5.753, de 12 de abril de 2006. Promulga a Convenção para a Salvaguarda do Patrimônio Cultural Imaterial, adotada em Paris, em 17 de outubro de 2003, e assinada em 3 de novembro de 2003. Diário Oficial da União, Brasilia, DF, 13 abr. 2006. Disponível em: http://www.planalto.gov.br/ ccivil_03/_ato2004-2006/2006/decreto/d5753.htm. Acesso em: 4 maio 2018.

BRASIL. Presidência da República. Decreto n. 7.387, de 9 de dezembro de 2010. Institui o Inventário Nacional da Diversidade Linguística e dá outras providências. Diário Oficial da União, Brasília, DF, 10 dez. 2010. Disponível em: http://www.planalto.gov.br/ccivil_03/_Ato2007-2010/2010/Decreto/D7387.htm. Acesso em: 2 maio 2018.

DEPARTAMENTO DE IDENTIFICAÇÃO E DOCUMENTAÇÃO - IPHAN. Inventário nacional de referências culturais: manual de aplicação. Braślia, DF: Instituto do Patrimônio Histórico e Artístico Nacional, 2000. Disponível em: http://portaliphan.gov.br/uploads/ckfinder/arquivos/Manual_do_INRC.pdf. Acesso em: 4 maio 2018.

FONSECA, M. C. L. "Da Modernização à participação: a política federal de preservação nos anos 70 e 80". Revista do Patrimônio Histórico e Artístico Nacional, Rio de Janeiro, n. 24, 1996.

FREIRE, J. R. B. A descoberta do museu pelos índios. Terra das Águas - Revista semestral do Núcleo de Estudos Amazônicos da Universidade de Brasília, ano 1, n. 1, 1999.

GALLOIS, D. T (org.). Patrimônio Cultural Imaterial e Povos Indígenas. Exemplos no Amapá e norte do Pará. São Paulo: Instituto de Pesquisa e Formação em Educação Indigena - IEPÉ, 2006. Disponível em: https://www.institutoiepe.org.br/media/livros/livro_patrimonio_cultural_imaterial_e_povos_indigenas-baixa_resolucao.pdf. Acesso em: 4 maio 2018.

GNECCO, C. La arqueología (moderna) ante el empuje decolonial. In: SHEPHERD, N.; GNECCO, C.; HABER, A. Arqueología y Decolonialidad. Buenos Aires: Ediciones del Signo, 2016.

GIL, C. Z. V.; POSSAMAI, Z. R. Educação Patrimonial: percursos, concepções e apropriações. MOUSEION, Canoas, n. 19, dez. 2014. Disponivel em: http://www.revistas.unilasalle.edu.br/index.php/mouseion. Acesso em: 2 maio 2018.

GONÇALVES, J. R. S. A Retórica da Perda. Rio de Janeiro: Editora da UFRJ, 2002.

HAFSTEIN, V. Celebrando as diferenças, reforçando a conformidade. In: SANDRONI, C.; SALLES, S. G. (org.). Patrimônio Cultural em Discussão: novos desafios teórico-metodológicos. Recife: Editora Universitária da UFPE, 2014.

IBGE. Censo 2010. 2010. Disponível em: https://censo2010.bge.gov.br/. Acesso em: 02 maio 2018.

INSTITUTO DO PATRIMÔNIO HISTÓRICO E ARTÍSTICO NACIONAL - IPHAN. Carta de Fortaleza. Nov. 1997. Disponivel em: http://portal.iphan.gov.br/uploads/ckfinder/arquivos/Carta\%20de\%20Fortaleza\%201997.pdf. Acesso em: 4 maio 2018.

MESTRE, J. S.; CARDONA, F. X. H. Museologia Crítica. Gijón: Ediciones TREA, 2006. 
MIGNOLO, W. La opción de-colonial: desprendimiento y apertura. Un manifiesto y un caso. Tabula Rasa, Bogotá, n. 8, p. 243-281, enero/jun. 2008.

MIGNOLO, W. “Aiesthesis decolonial”. CALE14, v. 4, n. 4, enero/jun. 2010.

ORGANIZAÇÃO INTERNACIONAL DO TRABALH0. Convenção n. 169. Brasília, DF: Organização Internacional do Trabalho, 2012. Disponível em: https://www.lo.org/wcmsp5/groups/public/---americas/---ro-lima/--ilo-brasilia/documents/genericdocument/wcms_648863.pdf. Acesso em: 2 maio 2018.

QUIJANO, A. Notas sobre a questão da identidade e nação no Peru. Estudos Avançados, v. 6, n. 16, p. 73-80, set./dez. 1992.

SALLES, S. G. Patrimônio Cultural, Representação e Poder: desafios à prática antropológica. Revista Raízes, v. 34, n. 2, jul./dez. 2014.

SANT'ANNA, M. A face imaterial do Patrimônio Cultural: os novos instrumentos de reconhecimento e valorização. In: ABREU, R.; CHAGAS, M. Memória e Patrimônio: ensaios contemporâneos. Rio de Janeiro: Lamparina Editora, 2009.

SANT'ANNA, M. Da cidade-monumento à cidade-documento: a norma de preservação de áreas urbanas no Brasil, 1937-1990. Salvador: Iphan: Oiti, 2015.

SANTOS, B. S. A Crítica da razão Indolente: contra o desperdício da experiência. São Paulo: Cortez, 2002.

TUBINO, F. Del interculturalismo funcional al interculturalismo crítico. In: SAMANIEGO, M.; GARBARINI, C. (org.). Rostros y fronteras de la identidad. Temuco: UCT, 2004.

WALSH, C. Interculturalidade Crítica e Pedagogia Decolonial: in-surgir, re-existir e re-viver. In: CANDAU, V. Educação intercultural na América Latina: entre concepções, tensões e propostas. Rio de Janeiro: Letras, 2009.

UNESCO. Convenção para a Proteção do Património Mundial, Cultural e Natural. De 16 de novembro de 1972. Disponivel em: https://whc.unesco.org/archive/convention-pt.pdf. Acesso em: 2 maio 2018.

YOUNG, R. J. C. Desejo Colonial. São Paulo: Perspectiva, 2005.

ZIZEK, S. "Multiculturalismo o la lógica cultural del capitalismo multinacional," en Estudios culturales. Reflexiones sobre el multiculturalismo. F. Jameson y S. Zizek. Barcelona: Paidós, 1998.

Endereços para correspondencia: Programa de Pós-graduação em Educação Contemporânea - Centro Acadêmico do Agreste, Av. Campina Grande, Rodovia BR-104, km 59, s/n, 55014-900, Nova Caruaru, Caruaru, Pernambuco, Brasil; sandro.ufpe@gmail.com 